\title{
VIAJEROS POR LOS PAISAJES DE ESPAÑA: DEL SIGLO XVIII A LA ACTUALIDAD
}

\author{
Félix Pillet Capdepón
}

Universidad de Castilla-La Mancha

\section{RESUMEN}

Continuando con los estudios realizados sobre los viajeros ilustrados y románticos por el conjunto de España, tanto extranjeros como españoles, haremos una relectura de estos autores, para detenernos en sus descripciones paisajistas, con el fin de seguir analizando el proceso durante el modernismo, el realismo social, el paisajismo franquista, y por último, la situación actual, donde tanto el hiperrealismo, como el neo-romanticismo vienen a demostrar que la literatura de viajes sigue vigente, aunque con enfoques distintos en los últimos momentos. El objetivo del estudio consiste en analizar a lo largo del proceso cómo fueron cambiando los medios de transporte y cómo los paisajes que interesaron a los viajeros pasaron de los naturales-rurales a los urbanos.

Palabras clave: Viajeros; literatura de viajes; paisajes; turismo; España.

\section{Travellers throughout Spanish landscapes: from 18th century to modern day}

\section{ABSTRACT}

As an extension of studies conducted on learned and romantic travellers around the whole of Spain, both foreign and Spanish, we will revisit and reinterpret the work from these authors in order to pause and focus on their landscape descriptions. By doing so, we aim to continue analysing the process throughout modernism, social realism, Francoist landscape and, lastly, the current context, where both hyperrealism and neo-romanticism jointly demonstrate that travel literature continues unabated, albeit by following different

Recibido: 16 de abril de 2015

Devuelto para su revisión: 20 de julio de 2015

Aceptado: 24 de septiembre de 2015

Departamento de Geografía y Ordenación del Territorio. Universidad de Castilla-La Mancha. Avda. Camilo José Cela, s/n. 13071 CIUDAD REAL.E-mail: felix.pillet@uclm.es 
approaches in recent years. The aim of the study entails continually analysing the changes that occurred throughout the process in terms of transport means and how the landscapes that captivated the travellers witnessed a shift from natural-rural to urban.

Keywords: Travellers; travel literature; landscapes; tourism; Spain.

\section{INTRODUCCIÓN}

La literatura de viajes es muy rica en contenidos y en información social, lo que nos obliga a centrarnos en un aspecto: la descripción de paisajes, sin olvidar los principales mensajes que de ella se derivan. Desde este planteamiento, en un estudio sobre los viajeros y el turismo, se han destacado tres grandes objetivos en el transcurrir del mundo: el viaje como saber estratégico desde los orígenes; el viaje como saber formativo desde el Renacimiento; y el viaje como placer estético y como divertimento desde el Romanticismo hasta la actualidad (Pillet, 2015a). Es nuestro propósito analizar la evolución viajera por España hasta nuestros días, tomando como referencia el siglo XVIII, tanto por el número de extranjeros que nos visitaron como por los españoles que comenzaron a salir fuera, tal y como se afirma en la obra realizada por la Biblioteca Nacional de España: Libros de viaje y viajeros de los siglos XVI-XIX (2013), recopilación que viene a continuar la labor de Farinelli (1920) y la de García Mercadal, escrita, esta última, desde 1917 a 1952, de la que nos ha quedado una última edición de 1999.

El Grand Tour del setecientos, el llamado «Siglo de los Viajes», convirtió el viaje en elemento esencial para el conocimiento del mundo y la sociedad. Desde comienzos del siglo siguiente y especialmente desde 1840 se publicaron numerosas guías, que sirvieron como orientación para nuevas iniciativas, otra cosa muy distinta, como ha afirmado Capel (2014: 113) fue el turismo organizado de Tomas Cook. En el balance sobre la literatura viajera ilustrada y romántica que nos ofreció López Ontiveros (2006) merecen ser recogidos los siguientes aspectos: se acepta que en los textos aportados por los viajeros pueden existir exageraciones, falsedades, subjetividad, pero está de acuerdo en que mientras el visitante observa, el de casa experimenta; de esta forma, nadie inserto en el paisaje lo ve como lo percibe el foráneo. Sobre los relatos ilustrados, afirmaba que eran geografía a todos los efectos. Respecto a los románticos, aunque aparecen transidos de subjetividad y de pretensiones estéticas, destaca el maridaje profundo entre el interés por el lugar específico y la conformación subjetiva y objetiva del paisaje. En España siempre nos interesó saber «cómo nos ven los extranjeros» (Campoy, 1963), posiblemente por una reacción negativa ante la opinión de algunos viajeros, como fue el caso de los llamados «curiosos impertinentes» (Robertson, 1988). Miguel de Unamuno aconsejaba, a comienzos del siglo $\mathrm{XX}$, que antes de salir a Europa debíamos viajar por nuestro país, pues estaba por conocer, para a continuación afirmar: «os aseguro que pocos países habrá en Europa en que se pueda gozar de una mayor variedad de paisajes que en España» (Unamuno: 2004: 302).

Por las razones antes expuestas, comenzaremos el recorrido desde mediados del siglo XVIII, conociendo la realidad española, destacando los grandes momentos de la historia, para luego contemplar directamente las obras de los autores, y no las recopilaciones de 
viajeros muy conocidos y citados, la visión de nuestro país, tanto por parte de los viajeros extranjeros como españoles. Para ello tomaremos como referencia las publicaciones sobre el conjunto del país, pues en ellas se aprecian mejor las diferencias regionales, a la vez que se citará de paso los viajes de españoles, tanto por el extranjero como los llevados a cabo por nuestras comarcas. Los viajes se hicieron primero en carro de caballos y en diligencia y posteriormente en ferrocarril; desde la segunda parte del siglo XX hasta la actualidad, en automóvil, y la llegada en avión permitió una primera percepción del país.

\section{LOS VIAJEROS ILUSTRADOS: SEGUNDA PARTE DEL SIGLO XVIII}

Al quedar España al margen del Grand Tour, debido a la leyenda negra, fue necesario esperar la segunda parte del siglo XVIII para recibir a los primeros visitantes, siendo ellos los que vendrán a romper los tópicos legendarios, sin olvidar las primeras salidas de españoles a Europa. El proceso de lenta transformación social vino de la mano de las Sociedades de Amigos del País que fomentaron el estudio de todos los sectores de la economía, especialmente de la agricultura, siendo la Iglesia y la nobleza los que poseían el control del poder y de las mejores tierras (Anes, 1969). A esta circunstancia se unió la transformación de los caminos en carreteras, lo que facilitó la llegada en diligencia de los viajeros ilustrados. España representaba para la intelectualidad europea un país inculto y fanático, acusando muchos de ellos a la Iglesia española de su retraso.

Aunque en el estudio de los viajeros se priorizará el interés mostrado por el paisaje, la única excepción se hará con el primero de ellos, pues al residir doce años entre nosotros (1777-89) como embajador de Francia, hombre de la Ilustración y posiblemente el que ofreció una visión más ajustada de la realidad, como ha señalado Ortas (2005), merecerá que recojamos los principales aspectos de su aportación, pues sin duda nos ayudará a conocernos. Nos estamos refiriendo a Jean-François Bourgoing con su Imagen de la moderna España (1789), reeditada en 2012. En ella podemos leer que nuestro país era «tan interesante como poco conocido». Resultado de su gran pasión por la objetividad, su fina ironía y culta observación, le llamó la atención que pese a su buena riqueza: natural, económica y artística, se encontraba aún bajo la influencia de La Mesta dando un excesivo peso a la ganadería, al «pasturaje», por lo que esperaba que la influencia de las Sociedades Patrióticas y de Amigos del País originaran el cambio hacia una agricultura moderna. Se centró también en su geografía abrupta y compleja, en las abismales diferencias regionales, y en su corrupta administración. Realizó su viaje entrando por el País Vasco y tras llegar al sur, deteniéndose ampliamente en la Villa y Corte de Madrid, volvería a salir por Cataluña y el Pirineo. En la obra se puede leer su visión real de la situación, mezcla de libro de viaje y de tratado sobre la sociedad:

«Creo haber demostrado que España y los españoles distan mucho de merecer el desdén con que los juzga la ignorancia... un designio fatal apartó hace tiempo a este país de la senda que debía seguir... Sus habitantes poseen una imaginación certera y profunda. Tienen aptitudes para todas las artes. Cuentan con esbozos de establecimientos en casi todos los géneros. Las fuentes de riqueza discurren a sus pies bajo suelos transparentes... Por árido que pueda parecer, vuestro país dispone 
en este campo de recursos mucho mayores de cuanto advierte el viajero apresurado. Está falto de sombra; secundad en fin por doquier el propósito del Gobierno de multiplicar los árboles» (Bourgoing, 2012: 931-943).

El primer gran viajero al uso sería el clérigo ilustrado Joseph Tonwnsend que demostró en sus Viajes por España (1786-87), su fino espíritu observador, pues supo plasmar sus conocimientos geológicos y humanistas, en un momento de auge del naturalismo. La buena acogida que tuvo su persona, por parte de la jerarquía eclesiástica y nobiliaria, le ayudó en sus desplazamientos, y le posibilitó forjarse una opinión certera sobre las mismas: la corrupción moral debida al «celibato del clero» y la existencia de una nobleza que «no vive más que para el placer». En su largo viajar entró por los Pirineos hasta llegar a Barcelona, recorrió parte de Cataluña, luego se trasladó hacia Madrid, pasando por Aragón, tras visitar muchos lugares de Castilla incluso de Asturias, para nuevamente desde Madrid descender hasta Andalucía, luego dirigió sus pasos por todo el levante, desde Cartagena hasta Barcelona. Se detuvo a estudiar la calidad del suelo, el tipo de materiales y en definitiva cómo el medio físico aparece como un claro condicionante, no sólo de la actividad agraria, sino también del emplazamiento de las ciudades y de la construcción de sus edificios. Las penalidades y fatigas que tuvo que soportar en su largo viaje se vieron complacidas con la perspectiva que le ofrece el paisaje o la visita a destacadas edificaciones, como fue el caso de la catedral de Zaragoza. Previamente había afirmado que la ciudad de Barcelona la «habría elegido como lugar de retiro». Demostró cierto interés por la zonificación urbana, pues cuando llega a Madrid la divide en «tres sectores fácilmente diferenciables y que se correspondían a otras tantas épocas». En Andalucía le llamaron la atención las calamidades sociales, pues junto a los mendigos que proliferaban por las ciudades, comprobó la evidente desigualdad de la concentración de la propiedad de la tierra, reclamando la necesidad de una clase agraria profesional, pues dicha ausencia provocaba el atraso social y la baja industrialización, situación que no había visto en Cataluña:

«No hay ningún país que sufra tanto como España las consecuencias de la falta de un poderoso grupo de arrendatarios ricos...las grandes propiedades están sujetas a un vínculo muy estricto y se encuentran administradas por cuenta del propietario, por lo que apenas queda tierra para alquilar a los granjeros, y menos aún susceptible de ser comprada por una persona adinerada, todo lo cual hace languidecer la industria. En Cataluña ocurre precisamente lo contrario» (Townsend, 1988, 197 y 423 ).

La minoría ilustrada de nuestro país entendió que viajar era un factor muy adecuado para el enriquecimiento cultural como demostraron: Viera y Clavijo, Fernández de Moratín ${ }^{1}$ y especialmente Ponz. Gómez de la Serna (1974) escribió que el viaje comportaba indagación e interés por ilustrarse, debiendo reunir entre otros aspectos: reformismo pedagógico y conciencia de la realidad. La obra viajera más importante se debe a Antonio Ponz, llevada a cabo por encargo de Campomanes. Sus cartas por ciudades europeas, espe-

1 José de Viera y Clavijo, viaja por España o más concreto por dos comarcas (1774-81) y por Francia y Flandes (1777-78); y Leandro Fernández de Moratín en su viaje a Italia (1792-96). 
cialmente a Roma ${ }^{2}$ y sobre todo de su Viaje de España (1772-94) destacan los siguientes temas de interés geográfico: la despoblación, la repoblación forestal, la mejora de la agricultura, la industria y la minería, los caminos y las obras hidráulicas, prestando un vivo interés por el análisis de la perspectiva paisajística y urbana. En el tomo cuarto de su obra plantea sus criterios sobre la planificación urbana, especialmente su consejo de que las calles «principales sean rectas y anchas», lo que hizo que Chueca Goitia (1968: 223-225) llegara a decir de él que era «el clasicista doctrinario, el espíritu pragmático, el filósofo con ribetes de arbitrista». Llama la atención que, aunque valenciano, las dos obras las iniciara comenzando desde Toledo, la vieja ciudad imperial, pues tanto Ponz como otros viajeros se interesaron mucho por su deplorable aspecto. De su Viaje de España recogeremos su obsesión por el trazado de las calles tomando como referencia a Madrid:

«Sin embargo de los defectos referidos, las calles son, por lo general, anchas, desahogadas y largas. $\mathrm{Si}$, poco a poco se fueren retirando algunas casas, adelantando otras y formando varios puntos de vista con abrir ciertas comunicaciones, se hallaría más variedad y gusto al caminar por ellas, pues no les falta razón a los que se disgustan por la demasiada igualdad y simetría, que, al fin cansa y fastidia» (Ponz, 1988, vol II: 24).

Cuando ya concluía el siglo XVIII fuimos visitados por el erudito, de formación lingüista, Wilhelm von Humboldt, hermano de Alexander ${ }^{3}$, que decidió realizar su Diario de viaje a España (1799-1800). Aunque su visión general fue bastante pesimista terminaría afirmando: «Es un país maravilloso cuyos habitantes amaré siempre». Desplazándose desde París, donde llevaba varios años viviendo, hizo su recorrido leyendo la obra de Ponz, iniciando su marcha por el País Vasco hasta Andalucía, deteniéndose en Madrid, para luego desde Murcia subir todo el levante y salir por Cataluña. Le agradó el País Vasco por sus montañas cubiertas de verde y los valles bien cultivados, sin olvidar la hermosa ciudad de Vitoria. El recorrido por Castilla fue decepcionante, tanto la parte septentrional «horrible desierto...campo raso... pocas aldeas y apenas ningún árbol», como la meridional «un auténtico desierto. Ni un árbol, ni un campo de cultivo, ni una aldea, sólo un par de alquerías aisladas... la tierra se abandona a ciencia y conciencia para que sirva de alimento a la caza». Lo mismo le ocurrió con las ciudades: la suciedad de Valladolid, la destrucción de Toledo, de Madrid no dijo nada ni a favor ni en contra, a pesar de haber realizado grandes contactos y entrevistas. El recorrido por Andalucía fue diferente pues pudo comprobar cómo las ciudades se rodeaban de huertos y los campos se cubrían de olivos y otros cultivos. Visitó muchos edificios singulares de sus ciudades, aunque le desagradó Córdoba, especialmente, así como Granada y Málaga. En su camino por todo el levante mediterráneo comprobó que Murcia era una de las ciudades más agradables que ha conocido, Valencia es la mejor construida, y Barcelona aunque no es bella ni limpia, es «un lugar grande y populoso, al que no le falta ni comercio, ahora un poco estancado, ni

\footnotetext{
2 Viaje fuera de España (1785).

3 En enero de 1799 llegó Alexander a España y una vez logrado el permiso real, inició su viaje a la Nueva España en junio. Entró por Cataluña, llegó a Madrid y salió de viaje a la nueva España embarcando en La Coruña, tal y como hemos descrito su travesía (Pillet, 2015a: 190).
} 
fábrica de lujo». En su trayecto por el reino de Valencia va observando un paisaje agrario que ciertamente le apasiona:

«Bien regado, con terrenos magníficamente cultivados, con naranjales cercados o viveros, palmeras que crecen en grupos... Es una zona feraz y tiene muchos cultivos, aunque en ninguna parte hay una vista tan rica en vegetación como en los alrededores de Valencia... Campos verdes bien cultivados, higueras que ahora empezaban a brotar, olivos en cantidades ingentes, naranjos, cipreses y palmeras» (Humboldt, 1998: 219-232).

\section{LOS VIAJEROS ROMÁNTICOS: SIGLO XIX}

Una vez expulsadas las tropas francesas de España, tras la primera década del siglo XIX, la situación era la siguiente: total descapitalización, colapso económico, población estancada y analfabetismo. El nuevo Estado Liberal, según Artola (1977) utilizó dos mecanismos para liquidar la deuda pública, en primer lugar, la contribución de las personas físicas; y en segundo lugar, la desamortización de los bienes del clero regular, pero el paso de tierras del clero a los mayores postores burgueses no incidió en la mejora de la agricultura, ya que continuaría descapitalizada y en secano. De esta forma, la agricultura quedó totalmente estancada, al mismo tiempo que la industria presentaba una situación claramente artesanal y de autoabastecimiento. La urbanización se desarrolló en dos fases, primero la reforma interior de las ciudades, y en segundo lugar, el derribo de las murallas y el posterior ensanche (Capel, 1975). Con la Restauración borbónica, el sistema económico dominante continuó siendo la agricultura, sobre la que recayeron continuas crisis agrarias y ganaderas. La paz política reinante favoreció el desarrollo del ferrocarril y la mejora de los secanos gracias a la filoxera francesa, según Martínez Cuadrado (1976). El proceso desamortizador, que comenzó perjudicando a la Iglesia, luego se extendería a gran parte de los municipios que vieron privatizarse sus tierras.

Los viajeros románticos conformaron la imagen literaria, el descubrimiento moderno del paisaje, desde una perspectiva inédita, tal y como señaló Ortega Cantero. Buscaban lo diferente y lo genuino, así como escenarios propicios para el ejercicio de la fantasía, la sensibilidad, la pasión, lo inesperado, incluso lo peligroso. España y muy especialmente Andalucía se convierten en el destino favorito, tras la Guerra de la Independencia (Ortega Cantero, 1990, 2003). Andalucía, según López Ontiveros (2001), que había sido destino de los primeros ilustrados, con los románticos su paisaje aparece transido de subjetividad y de pretensiones estéticas, mostrando una concepción claramente «oriental», pues se podía observar en el sur de Europa las esencias y construcciones del mundo árabe. Los principales representantes, tanto ingleses como franceses, fueron: George Borrow (1843), Richard Ford (1845) y Téophile Gautier (1845).

De los viajeros románticos, no cabe duda que Richard Ford fue quien, con su magistral narración de viajes, ha ejercido una mayor influencia con su Manual para viajeros por España (1845), pues tras varios viajes por Europa (1815 y 1822) vendría a recorrer España (1830 y 1831), y una década después se comprometería a escribir su Manual, resultado de sus datos recogidos y sus dibujos a lápiz, reuniendo un total de 1.064 páginas, fue un gran 
éxito de venta, gracias a su agudo pensamiento y humor chispeante, que venía unido a su amor por España. Comienza hablando de: «Este país, el más romántico y característico de Europa». Tras señalar los distintos tipos y maneras de viajar, indicará que el clima del país es muy desigual, la península es «una montaña o aglomeración de montañas... siete cadenas distintas de montañas». Si los románticos buscaban países montañosos y ciudades con encanto, esta será la recomendación más general que nos ofrece:

«Los principales puntos de interés de la Península son Andalucía, Madrid, donde hay que incluir Toledo, Ávila, Salamanca, Valladolid, Segovia, El Escorial, Cuenca y Guadalajara, y luego Valencia, que comprende también Tarragona, Zaragoza, Montserrat y Barcelona. Los que pasen de Andalucía a Madrid encontrarán que el camino por Extremadura está lleno de interés, mientras que en La Mancha, si exceptuamos el encanto ideal que le da don Quijote, resulta en general monótono y aburrido. Extremadura bien merece una visita por si sola y los que desembarquen en Lisboa podrían entrar en España por Badajoz. Mérida es una segunda Roma y contiene ruinas de todas clases, muchas de ellas en admirable estado de conservación» (Ford, 2008, I: 185).

El último viajero extranjero romántico fue el aristócrata francés Charles Davillier acompañado del dibujante Gustave Doré, que ayudaría con sus ilustraciones a entender perfectamente el recorrido. Ambos dieron como resultado la mejor obra viajera, exenta de exageraciones y muy ajustada a la realidad del país, como se comprueba con la atenta lectura de Viaje por España (1862-73), donde demuestra, entre otros aspectos, haber leído a Ponz y Gautier. Nos ofrecen el recorrido más extenso, tanto en diligencia como en ferrocarril, llegando incluso a coger el barco para desplazarse a Palma de Mallorca. En Cataluña recomienda visitar Gerona, de Barcelona indica que es el primer puerto del reino, similar a Marsella; los campos circundantes presentan masas grisáceas de olivos, campos de algarrobos, el verde follaje sombrío de los naranjos y por último, la fértil campiña del Llobregat. Por su parte, las huertas valencianas se extienden con cultivos de arroz y naranjales en campo abierto, junto a una serie de ciudades industriales, donde destaca la capital. Descendiendo por el levante aparece Alicante, ciudad moderna y comercial y Murcia con sus fértiles alrededores. Previamente ha conocido el interior al pasar por Albacete, donde en el secano alternan la abundancia de cardos y los extensos campos de trigo, le llaman la atención las fábricas de navajas y cuchillos. En Andalucía hace referencia a sus ciudades: de Cádiz y de Sevilla destaca el que sean las más antiguas de Europa, y de Córdoba, su pasado glorioso. Por Sierra Morena conectará con La Mancha: «No se puede uno figurar un cambio más súbito ni completo», llanuras inmensas, desnudas y áridas, expuestas a todos los vientos y quemadas por el sol, ciudades y pueblos con aspecto de pobreza, a lo que se unió el haber sido asaltados por los mendigos, destacando a Valdepeñas por estar rodeada de viñas. Luego entraría a conocer Extremadura, destacando la antigüedad de Mérida, para salir con impaciencia para llegar a Toledo «ciudad pintoresca y romántica por excelencia», y sobre todo Madrid, donde le sorprende la escasa altura de sus edificios, pues la mayor parte tenían una planta, siendo por tanto una ciudad atrasada. De sus alrededores cita al Escorial, 
Segovia, Alcalá de Henares y Cuenca. Las ciudades de Castilla la Vieja le parecen tristes, menciona la catedral de Burgos, única en España, y la ciudad activa y laboriosa de Valladolid. A través de León llega a Galicia, de Santiago de Compostela dice que solo tiene notable su famosa catedral. Posteriormente continúa su viaje pasando por Navarra, Aragón, donde dice que Zaragoza es una de las ciudades más interesantes de España. Las provincias vascas las ve como las más aferradas a sus tradiciones, mientras los alrededores de San Sebastián le recuerdan a Suiza; de Bilbao y Vitoria, cita su original aspecto y su oscuridad silenciosa, respectivamente. El largo viaje concluye en Palma de Mallorca, cuyas islas son rara vez visitadas por los turistas según él, con el bagaje de todo el trayecto no sólo observa cuanto ve sino que también hace curiosas comparaciones con el levante valenciano:

«Lo que más sorprende cuando se desembarca en Palma es la calma que reina en la ciudad, calma que contrasta con el movimiento y actividad de Barcelona... Abundan las casas antiguas en Palma. Muchas tienen un tejado en saledizo apoyado en dos vigas adornadas con esculturas... Por la tarde fuimos a pasearnos por los alrededores de la ciudad, que son los más hermosos del mundo y muy parecidos a los campos del reino de Valencia» (Davillier, 1998, II: 448-452).

La influencia de los románticos se dejó sentir en un buen número de viajeros españoles que iniciaron sus recorridos por Europa ${ }^{4}$. De la misma forma que en el siglo anterior destacábamos la figura de Ponz, ahora podríamos mencionar, en menor medida, la obra de Pedro Antonio de Alarcón que desarrollaría su viaje De Madrid a Nápoles (1860-61), su recorrido por una comarca de su provincia, como fue La Alpujarra (1873) y sobre todo sus Viajes por España (1883). En esta última obra realiza un balance o cuadro general de sus «correrías» por la mayor parte del país, desde mediados de los cincuenta hasta comienzos de los ochenta, aunque por razones de edad no llegó a escribir sus «andanzas» recogiendo tan solo algunos ejemplos, los de la primera época, por lo que existe en ellos mayor carga romántica que realista. Su punto de partida sería la «prosaica y anti-artística villa de Madrid». En un viaje en dirección a Yuste hace referencia a la famosísima Vera, país de fertilidad, una «especie de Alpujarra chica». En su viaje en ferrocarril a Salamanca por «camino de hierro» nos describe ampliamente una ciudad que no sólo la considera monumental sino que es un «Museo arquitectónico». En otro viaje en ferrocarril hacia Santander, aunque frustrado por accidente: «nuestro wagón se balanceaba sobre el abismo», llamará a Valladolid la «Sevilla del Norte» aunque con fábricas a pequeña escala. En la provincia de Palencia observa que las llanuras castellanas se «accidentan» debido a que «el suelo se quebranta y empieza a rizarse en valles y colinas». Y por último, sobre Toledo, «la vetusta ciudad imperial» tras compararla con las mejores ciudades españolas señalará que «Toledo lo encierra todo» pues su historia está escrita en innumerables documentos. Le llama la atención el poco interés de los españoles por viajar, pues iban solos en el vagón del tren:

4 Ramón Mesonero Romanos, a Francia y Bélgica (1840-41) y Emilia Pardo Bazán, a París (1889). 
«Los españoles tenemos pocos asuntos fuera de casa, y los que tenemos no nos interesan hasta el extremo de hacernos emprender largos viajes. Nuestra filosofía moruna, ascética, ó como queráis llamarla, da de sí esta magnánima indiferencia, tan deplorada por economistas y políticos, y tan aplaudida por otra clase de pensadores que miran las cosas desde más alto. Viajan, sí, por mero placer, los elegantes y los fantaseadores, los bañistas de afición y los amantes de la naturaleza» (Alarcón, 1883: 85).

\section{LOS VIAJEROS DEL MODERNISMO Y DEL REALISMO SOCIAL: FINALES DEL XIX HASTA MEDIADOS DEL SIGLO XX}

El modernismo supuso la primera toma de contacto con el exterior, para la burguesía y la aristocracia. Las primeras décadas del nuevo siglo se caracterizaron por una economía claramente de crisis, debido a la fuerte caída de la producción agraria, situación que se intentó remediar con el inicio de un proceso de industrialización. Con la dictadura de Primo de Rivera, coincidiendo con la ola de prosperidad exterior, todo continuaría por hacer, a excepción de las importantes obras públicas, al tiempo que se produjo un considerable incremento de la población y un trasvase desde el campo a la ciudad, lo que originó zonas de expansión o ensanche en el extremo de los núcleos urbanos, facilitando el crecimiento más que ordenándolo, dando lugar a urbanizaciones marginales inconexas y carentes de servicios. El gobierno de la República, según Tuñón de Lara (1974), en medio de una profunda crisis económica internacional, quiso llevar a cabo la reforma agraria, pero quedó frenada con la guerra civil y la llegada del franquismo. Las ciudades vieron nuevos estilos arquitectónicos que vinieron a sustituir al modernismo, nos estamos refiriendo al racionalismo de la Gatepac $^{5}$. Tras la guerra civil, unos emigraron y la mayor parte se quedaron, estos últimos se vieron encerrados como en una cárcel, pues los movimientos migratorios, tanto interiores como exteriores estaban prohibidos, nos encontrábamos en plena autarquía franquista.

El poeta belga Emile Verhaeren, uno de los fundadores del modernismo, y el pintor vasco Dario de Regoyos recorrieron nuestro país en 1888. Como resultado del viaje, Regoyos recogería las impresiones de los dos en el libro España negra (1899), nos centraremos más en lo que llamó la atención al poeta extranjero. Comienzan criticando a los viajeros anteriores, pues señalan que buscaban el confort, la comodidad «ellos y los ferrocarriles han vulgarizado la pasión de los viajeros», combinaron para su recorrido, desde el País Vasco hasta Madrid, la diligencia o más bien «un armario» tirado por caballos y mulas, y luego el ferrocarril. Por la costa cantábrica vasca encuentran paisajes de colinas verdes, pueblos con iglesias barrocas y casas solariegas, calles donde «los tejados se dan como cornadas de borregos», balcones que avanzan hacia la mitad de la calle, y puertos sucios y abandonados. Llamaba la atención los cementerios, las iglesias y las imágenes, todo de una gran negritud, así como los carros de ruedas planas sin rayos tiradas por bueyes. En el recorrido, los pueblos daban sensación de abandono, Sigüenza lo presentan como desvencijado, «cayéndose a pedazos». Madrid le pareció al belga un pueblo grande «pero sin la sensación que da un gran centro europeo», y el paisaje castellano estaba compuesto de:

5 Grupo de Artistas y Técnicos españoles para el Progreso de la Arquitectura Contemporánea. 
«Algunas encinas, pinos y otros árboles de follaje oscuro; troncos como brazos desesperados en posturas retorcidas, es la única vegetación de aquel paisaje... la Sierra con las vibraciones rojas de los últimos rayos del sol, y, más allá aún, otra cadena ondulada de montañas de un azul negruzco y lúgubre» (Verhaeren y Regoyos, 1963: 70).

Durante las primeras décadas nos visitaron una serie de viajeros extranjeros que se interesaron por las ciudades españolas. En primer lugar tendríamos que citar a los alemanes Klein (1907) y Maier-Graefe (1910), ellos fijaron su mirada en Barcelona y Sevilla, a las que se unía Madrid, especialmente por la necesaria visita al Museo del Prado, sin olvidar: San Sebastián, Salamanca, Toledo y Granada (Cerrolaza, 1993). Con mayor profundización en su análisis, podríamos citar al lingüista francés Albert Dauzat (1911) que escribió una obra donde analiza para qué se viaja. Demostró su poco interés por Madrid, llegando a afirmar que Barcelona debía ser la capital de España, pues representa el porvenir, al tiempo que el pasado lo escenifican Burgos, Toledo, Córdoba y Granada. De San Sebastián dirá que era la ciudad más elegante y coqueta, con un puerto pintoresco. Y por último, de Sevilla, señalará que pasaba por ser la mejor conservada de Andalucía. Aspectos que se desprenden de la recopilación de viajeros contemporáneos realizada por Flores (1972).

Miguel de Unamuno, uno de los paisajistas del 98, nos ofrece dos libros de viajes: Por tierras de Portugal y de España (1911) y Andanzas y visiones españolas (1922). Ambas recogen una serie de textos de sus «excursiones» y «correrías», palabra esta última ya utilizada por Alarcón. Interesado por la «variedad de paisajes» en general, pero también por la visita a las principales ciudades, contrastando la vida de las grandes ciudades respecto a las pequeñas, manifestando su constante dolor por el escaso avance de España: «cada uno de estos viajes que hago por nuestras capitales de provincia me llena de cierto pesar no exento de hondas inquietudes». Sin llevar un itinerario geográfico claro, comenzará con un texto sobre Barcelona, la «hermosa ciudad» con «un espléndido ensanche, con calles y avenidas realmente suntuosas y realzadas por fachadas magníficas, de un lujo deslumbrador». Relaciona Santiago de Compostela con Salamanca, «las dos ciudades españolas... que más parecido guardan entre sí». Ávila la considera «la ciudad murada», mientras que Palma de Mallorca le ofrece calma y bienestar, Gran Canaria la conoció pero no le interesó. Los paisajes que le merecen mayor interés son sin lugar a dudas Gredos «la majestad de Gredos» y la montaña cántabra. Compara Galicia con el País Vasco, las montañas viejas respecto a las jóvenes alpinas, respectivamente: «el país vasco está más al descubierto el pelado espinazo del Pirineo cantábrico; es todo más anguloso, más hosco, más juvenil y berroqueño; los valles más estrechos y las montañas más altas y empinadas». Como también hizo Alarcón, se dirigió a Extremadura y en concreto a Yuste y sus alrededores: «los caminos para llegar a Yuste son malos, escarpados y pedregosos...el paisaje de Jarandilla es una delicia de fresco verdor. Y esta hermosísima Vera de Plasencia languidece en triste atraso». Y por último se fija en una comarca, tal vez la más pobre de España, con el objetivo de destacar su riqueza paisajística, nos referimos a Las Hurdes ${ }^{6}$ «lejos del mundo bullanguero»:

6 La comarca de Las Hurdes fue visitada en 1922 por Gregorio Marañón acompañado al rey Alfonso XII, dejando constancia escrita de dicho viaje. 
«Los tesos, collados y montañas se entreabrazaban unos con otros. En su disposición general forman las Hurdes tres hondos valles casi paralelos... Difícilmente se encontrará otra comarca más a propósito para estudiar geografía viva, dinámica, la acción erosiva de las aguas, la formación de los arribes, hoces y encañadas. Y una maravilla de espectáculo a la vista, ya desde lo alto se dominan las hondonadas y el vasto oleaje petrificado de las líneas de las cumbres, ya desde los barrancos se cree uno encerrado lejos del mundo de los vivos que leen y escriben» (Unamuno, 2004: 467).

John Dos Passos, que destacó por sus preocupaciones sociales, nos ofrece su libro de peregrinaje por España: Rocinante vuelve al camino (1923). En sus páginas encontramos dos aspectos que nos interesa destacar, en primer lugar la presencia de una ciudad: «Barcelona, con su hermoso puerto anidado entre las altivas laderas de Montjuich». En segundo lugar, su constante insistencia en las grandes diferencias paisajísticas entre regiones: «una hora de tren basta para transportarle a uno desde la nieve de Siberia hasta el desierto africano», para añadir que «cada región está separada de cada otra por hondas gargantas y desfiladeros, candentes en verano y helados en invierno». Mientras que la provincia castellana de Toledo presenta «campos pardos entre el marrón oscuro de la tierra removida de las viñas», Andalucía ofrece «fértiles llanuras regadas, secos olivares que se extienden hasta las rocosas montañosas sedientas donde están las minas». Y por último, en la parte más occidental, en el levante mediterráneo, en contacto con las dos regiones anteriores se produce lo siguiente:

«Desde el Tajo al Mediterráneo se extiende una región montañosa donde llueve poco, entrecortada por varias series de amplios valles que, cuando regados, producen en gran cantidad arroz, naranjas y, en los terrenos más elevados, trigo. En las colinas secas crecen viñas, olivos y almendros» (Dos Passos, 1943:96).

El inglés Laurie Lee vino a España en 1931, según recoge la tesis doctoral de Jesús Martínez Alonso (2003) dirigida por Jaime Cerrolaza, y volvió poco antes de iniciarse la guerra civil movido por la realidad social, escribiendo sus experiencias casi cuatro décadas después. Acompañado de su violín y en pleno verano, parte de Galicia y llega hasta Andalucía. Sobre Castilla deja constancia de la decadencia de Zamora; le llama la atención los alrededores de Segovia y en concreto la Sierra de Guadarrama pues le recuerda al País de Gales. De Toledo sólo menciona el interés por El Greco; y Valdepeñas le parece un oasis de riqueza, debido a la abundancia y bienestar que observa, dado que está viviendo el esplendor de los beneficios de la filoxera francesa. Por último, sobre Andalucía, se centra primero en Sevilla pues la encuentra deslumbrante, símbolo de comodidad, y de Cádiz dice que huele a pescado. Comprueba que en el sur una pequeña parte de la sociedad vive injustamente a costa de la otra.

Al pintor y escritor santanderino José Guiérrez-Solana le impresionó la breve obra de Verhaeren y Regoyos y decidió recoger su experiencia viajera durante tres décadas en $L a$ España Negra (1900-20) y La España Negra (II) Viajes por España y otros escritos (191336). En el prólogo de ambas obras, Trapiello afirma que retrató el funebrismo español, 
siendo el pintor de la realidad, de una España real y sagrada, que es negra, pero no peor que otros países. Comienza el recorrido en Santander, indica que se están produciendo muchos cambios, auque prefiere como estaba antes, lo que demuestra cierta nostalgia. En Medina del Campo puede observar el paisaje de Castilla «desprovisto de árboles y llano como la palma de la mano». Hace referencia a un buen número de núcleos y ciudades: Valladolid era un «poblachón grande y rico»; Tembleque destaca por su pintoresca plaza; Plasencia, por ser una ciudad dividida por un puente de piedra; Calatayud, por ser un pueblo raro y de ensueño; Cuenca, por sus casas encaramadas en una montaña, que dan vértigo; de Toledo señala lo antipático del mercantilismo de sus monumentos. Luego hace referencia a dos grandes vías: la Gran Vía de Barcelona le parece desagradable y llena de edificios cursis; y respecto a la de Madrid, tras recorrerla en tranvía de mulas, hace referencia a los cambios en la ciudad y a los perjuicios a los vecinos:

«Para que puedan continuar con toda rapidez las obras del tercer trozo de la gran Vía... Esta manera alarmante de reformarse Madrid en todo y ponerse al nivel de las grandes ciudades europeas no nos va a dar resultado pues Madrid siempre ha sido chico, pobre y sin condiciones para ello. Hay quien cree que hemos salido ganando, pero para lo que ha servido tanto adelanto no ha sido más que para aumentar las contribuciones y hacer que cuesten los alimentos cuatro o cinco veces más que antes» (Gutiérrez-Solana, 2007: 304).

Dos viajeros ingleses del realismo social que habían conocido el país durante los años de la República volverían a visitarnos durante el franquismo, con el fin de publicar sus experiencias en los años cincuenta, nos referimos a dos buenos amigos entre si: Gerald Brenan y Sir Victor S. Pritchett.

El corresponsal y viajero Gerald Brenan en La faz actual de España (1950) inicia su diario con una frase claramente laudatoria, para alguien que nos conoce bien: «Los españoles son un pueblo muy notable y su país es uno de los más hermosos del mundo», pero no por ello deja de resaltar la dura y desigual situación de la postguerra. Lo presenta sumido en la miseria, el hambre y la pobreza, junto a una minoría que se enriquece. Antes de aterrizar en Madrid le llama la atención la «meseta oscura, de un gris plateado, tachonada de rocas sueltas y de manchas de nieve», en definitiva, una sucesión de «mesas» con ausencia de vegetación. De Madrid dice que si no fuera por el Museo del Prado no retendría a los visitantes, la Gran Vía le pareció una «calle vulgar y barullera de rascacielos enanos que atraviesa un viejo distrito», y Aranjuez lo denomina el «Versalles español». Su visión de Castilla la Nueva se concreta en la referencia al paisaje de meseta o monótona llanura de La Mancha, y a las desnudas y áridas sierras que separan La Mancha de Extremadura. Al paso por algunas ciudades menciona, entre otras a Toledo «una ciudad extraña, sombría y hasta casi siniestra», Badajoz le impresionó más de noche que de día «es una aburrida ciudad provinciana». Pasado Despeñaperros recorre una región ondulada, plantada de olivos, y campos cuidadosamente cultivados. Le llamará la atención los mendigos y la pobreza de Granada y Málaga, Córdoba le pareció una gran ciudad, visitó La Mezquita, «el más original y más hermoso» de los edificios de España. Pudo comprobar que Andalucía, 
especialmente, y otros lugares estaban necesitados de una reforma social y técnica de la tierra, a la vez que se debía eliminar la nueva corrupción creada por el sistema franquista:

«Lo que hace falta es una completa reorganización del sistema del cultivo de la tierra, unida a una fuerte presión sobre los terratenientes...todos los jefes falangistas, que antes de la guerra no tenían nada, son hoy hombres ricos, con casas y vastas propiedades...se han dejado arrastrar por la ola general de mercado negro y corrupción...La tierra nunca ha estado tan bien cuidada y, sin embargo, la mitad de la población está con hambre. Y si se pone fin al mercado negro, la clase media será también en seguida una clase de hambrientos...Las dos fuerzas de España que representan algo más que intereses monetarios son la Iglesia y la Falange... Esta miseria de la clase media me emociona todavía más que la de los obreros... Pero lo más terrible es que el hambre está haciendo de la vida familiar un infierno» (Brenan, 1964).

El corresponsal británico Sir Victor S. Pritchett publicaría pocos años después El temperamento español (1954). Conoció a los de la generación del 98 y eso le cambio la vida, de hecho reconoció que de todos los países visitados «España es el que me ha causado una mayor impresión». Desde el avión «España es de color marrón rojizo, amarillo y negro», luego se adentró por la «extraña meseta lunar y las montañas serradas de Castilla. Aquel paisaje me estimuló la imaginación. Anhelaba recorrerlo a pie». Los vascos, asturianos y navarros disfrutan un clima benigno donde llueve de manera tan regular como abundante. Castilla es una estepa moteada de naturaleza salvaje, donde los árboles sólo aparecen bordeando los caminos, su paisaje alterna aldeas ocultas, riachuelos, campos de cereal, y montañas afiladas y peladas. Madrid pasó de ser una ciudad anodina a ser una ciudad moderna, el franquismo ha levantado horribles y enormes monumentos públicos «esa calle absurdamente sudamericana que aún se llama Gran Vía se ha prolongado y completado». La Mancha, por su parte, «pese a un sol de justicia, es más verde que la vieja Castilla, pues las viñas bajas cubren aquí kilómetros y kilómetros de campo». En Andalucía sus habitantes se contentan «con lo mínimo para sobrevivir», Sevilla es una ciudad que da gusto recorrerla y verla; Granada tiene una calle principal que es una próspera arteria «a lo Oxford Street, a la que aún no le ha caído encima la maldición de los grandes almacenes», en Almería «cálido puertecillo marino» empieza el oasis. Murcia ofrece una huerta donde destacan las higueras, los olivos y las viñas, el núcleo urbano presenta el siguiente aspecto: «ciudad marrón, con sus tejados bajos embaldosados, yace desperdigada en torno a las iglesias». Más importancia otorga a la huerta valenciana «el terreno más fértil de España y el más intensamente cultivado de Europa», donde naranjales y arrozales se combinan, de la ciudad de Valencia dice que es una versión reducida de Madrid. De Cataluña destaca sus playas, al tiempo que sitúa a Barcelona como una gran fábrica textil, indicando que con Bilbao es la única ciudad industrial de peso en España, sin olvidar su importante puerto, concluyendo con la importancia de su planificación urbana:

«La parte moderna de Barcelona, al norte de la plaza de Cataluña, es un ejemplo de planificación a lo grande. Amplios bulevares recorren el largo ascenso hacia 
las montañas. Hay rotondas como desiertos en las intersecciones. La ciudad ha sido construida para una era motorizada que no ha llegado en serio a España. Por las calles no se ve ni un coche español. En el Paseo de Gracia, hay manzanas de pisos edificados por la fantástica escuela de arquitectos que vivieron su apogeo a principios de siglo, muy influenciados por el Art Nouveau» (Pritchett, 2015: 228).

\section{LOS VIAJEROS DEL PAISAJISMO FRANQUISTA: SEGUNDA PARTE DEL SIGLO XX}

El paso de la Autarquía al Plan de Estabilización (1959) supuso la puesta en vigor de los llamados planes de «desarrollo», aunque en realidad fueron de crecimiento desigual, pues mientras unas ciudades y lugares se transformaban y modernizaban, otras, las poblaciones rurales se vieron obligadas a emigrar hacia los núcleos urbanos, polígonos industriales y zonas turísticas, al tiempo que se generó una clara dicotomía campo-ciudad. De esta forma, el modo de producción dominante llevó a cabo un nuevo modelo de ciudad, que vino a generar barrios en las periferias de todas las capitales de provincias, a la vez que producía el deterioro del patrimonio construido y en otros casos su abandono. La vivienda se convirtió en una auténtica mercancía, poniendo los medios legales para que todos los ciudadanos fueran propietarios, lo que produjo un gran endeudamiento familiar. El recién creado Catastro Parcelario no sólo retrató la injusta distribución de la propiedad en manos de unos pocos, sino que al mismo tiempo se produjo la total privatización del suelo urbano destacando la importancia del capital financiero e inmobiliario como principales agentes transformadores, una estructura de la propiedad que ha condicionado a las décadas posteriores hasta la actualidad (Pillet, 2012). Los dos ingresos fundamentales del Régimen provenían de los emigrantes en Latino América y en Europa y de los turistas europeos que nos visitaban.

El paisaje y el paisajismo no sólo se convirtieron en recurso turístico durante el Franquismo, explorando las «topografías patrióticas» (Torres, 2015: 1242) sino que también muchos escritores de la literatura del momento acudían a él para eludir otras problemáticas, transformando los concursos literarios en auténticos juegos florales de exaltación del medio circundante. Por su parte, el viaje se convirtió en una defensa del «espacio político nacional-católico», la poética del viaje fue al mismo tiempo una política y una ética, una voluntad misionera de acercamiento al prójimo para evangelizarlo, de hecho la dictadura subvencionaría gran parte de los viajes de intelectuales por América desde el Instituto de Cultura Hispánica según Carrión (2011: 281). Entre los viajeros franquistas más destacados, por haber desarrollado sus viajes por el extranjero, se encuentran: el periodista Valeriano Salas (García y Marías, 2011) y el corresponsal Julio Camba, del que se ha realizado una obra con su aportación ${ }^{7}$.

Dos narradores españoles vinculados con el régimen llevaron a cabo desde mediados del siglo XX sus viajes por el conjunto de España, donde podríamos decir que vieron sin mirar la situación social. Nos referimos a Víctor de la Serna y a Camilo José de Cela, ambos estuvieron influenciados y agradecidos a Gregorio Marañon por su interés por el

7 Julio Camba: Crónicas de viaje. Impresiones de un corresponsal español (2014). 
viaje. A estos dos podríamos añadir al madrileño Edgar Neville, por su obra Mi España Particular (1957) pero más que un libro de viajes es una guía turística y gastronómica. Junto a los dos viajeros por el conjunto de España, otros, durante los años sesenta, se limitaron a viajar por distintas comarcas españolas: Las Hurdes, nuevamente, Campos de Nijar, el Valle de Alcudia y La Tierra de Campos ${ }^{8}$.

Víctor de la Serna en Nuevo Viaje de España. La ruta de los foramontanos (1955) y Nuevo viaje de España. La vía del Calatraveño (1960) nos aporta dos grandes bloques de artículos publicados previamente, con el objetivo de «navegar sin violencia hacia el amor y el entendimiento total de este país». En su primera publicación parte de Cantabria, atraviesa el Ebro para entrar en Castilla donde se va presintiendo el llano, a partir de cerros redondos, casi femeninos. La recorrerá descendiendo de norte a sur, y de este a oeste hasta León, considerada una ciudad antigua al tiempo que «una bellísima ciudad moderna». Recorriendo pueblos y comarcas, escrito todo ello con todo detalle y buena redacción, concluirá el primer viaje, año y medio después, en Pravia (Asturias). En su segunda oferta, contemplará La Mancha y parte de Andalucía, quedando sin concluir el trayecto por su fallecimiento. Comienza afirmando que «La Mancha tiene tal prestigio que todas las comarcas circunvecinas quieren ser llamadas manchegas» se refiere al Valle de Alcudia, al Campo de Montiel y al Campo de Calatrava, de esta última señalaba que es una «enorme vega» donde se pierden de vista los olivares, los viñedos y los trigales, destacando en el paisaje Almagro. En Andalucía hace mención a Málaga y su Costa del Sol y a Jerez:

«Y también ofrezco a Jerez la noticia de que no sólo ella está influida por la sangre castellana, sino que Castilla la marítima está influida por Jerez de una manera visible. Está influida en la arquitectura, en el amor a las flores y en el cuidado del vino» (Serna, 1960: 170).

Camilo José Cela, autor de los tres volúmenes de Viajes por España (1948-1964) recopilados en su obra completa, desempeñó el cargo de censor durante el régimen franquista, fue importante narrador y por último, Premio Nobel de Literatura (1989). En su obra viajera ${ }^{9}$ no sólo tuvo presente a Gregorio Marañón sino también a su padre «profesor de geografía». Inicia sus páginas con la siguiente afirmación: «Se camina con la mochila al hombro y -si se puede- también con una paz infinita en el corazón». Unas veces se autodenomina «vagabundo» y otras «viajero». Su primer recorrido fue el «Viaje a la Alcarria» que realizaría en 1946 y que cuarenta años después volvería a retomar, motivo por el cual lo dejaremos para el final con objeto de comparar ambos textos y especialmente, para ver el paso del tiempo sobre un mismo paisaje. Al viaje por una comarca castellana, se unió como segundo recorrido el realizado por las tierras del norte, desde Galicia hasta la raya de Francia donde La Coruña aparece como «una ciudad alegre, abierta y decidora», y

8 Caminando por las Hurdes de Ferres y López Salinas (1960), Campos de Nijar de Juan Goytisolo (1960), Valle de Alcudia de Romano y Sanz (1967) y Tierra mal bautizada. Un viaje por Tierra de Campos de Jesús Torbado (1969).

9 En Páginas de geografía errabunda (Cela, 1965) recogió breves reflexiones sobre los paisajes visitados, que publicaría en los diarios. 
Santander «una ciudad en la que se está demasiado bien», dos de las más bellas ciudades de España, según él. Por un camino abrupto y accidentado, con fábricas por todas partes y alguna playa concurrida recorrerá el norte para dirigirse hacia el Pirineo hasta el río Garona que «es español hasta el puente y francés después del puente». Cuando entra en Castilla, comienza por Guadarrama, siguiendo por el Puerto de Navacerrada hasta el Duero para concluir en Gredos «espalda de Castilla». La Mancha la considera tierra de paso llamándole la atención «la enrevesada telaraña del Guadiana... tomando a cachondeo a los geógrafos». Ya en Andalucía observa el Guadalquivir «río que se enseña turbio y manso y reposado fluir», y el mar de olivos. Las ciudades andaluzas le llaman la atención: Córdoba donde «el silencio es algo muy cotizado», Sevilla «la más bella ciudad», y Huelva «no es ciudad monumental; Huelva es ciudad humana». De su Viaje a la Alcarria haremos una lectura conjunta del realizado en 1946 y en 1985. Ya en su primer recorrido reconocía que era «un hermoso país» poco visitado. En ambas ocasiones la Alcarria visitada se limitó a la provincia de Guadalajara, olvidando la Alcarria de Cuenca, que otros han completado el territorio $^{10}$. El viaje se inicia por la Campiña del Henares, concretamente en Torija donde se ubica el Museo del Viaje a La Alcarria. Entra en la comarca por Fuentes de la Alcarria donde existe «un buen mirador», continúa por el conjunto histórico de Briguega que está en un «hondón», tras pasar por Cifuentes, con río de igual nombre, le llamará la atención en Trillo un curioso elemento natural: Las Tetas de Viana con «forma de cucurucho cortado» y las dos torres humeantes de la central nuclear. A través de meandros y embalses del Tajo irá recorriendo pequeños pueblos (Pareja, Sacedón, Tendilla y Pastrana), y los que utilizan en su nombre la palabra Zorita. De su Nuevo viaje a la Alcarria recogemos este texto donde se aprecia el paso del tiempo y su constante referencia a los ríos y a los instrumentos de regadío:

«Al Tajo, que por aquí pasa sosegado y majestuoso, se debe caer bien desde el puente, que tiene un solo ojo y es de sólida sillería mora y elegante trazo y silueta; por aquí hubo mucha industria, puede que más por el Cifuentes que por el Tajo, sierras de agua, aceñas, azudes y batanes a los que fue barriendo la escoba del progreso, es un decir» (Cela, 1987: 126).

\section{LOS VIAJEROS HIPERREALISTAS Y NEORROMÁNTICOS: LA TRANSI- CIÓN DE UN SIGLO A OTRO}

La democracia española supuso un importante cambio en la configuración del territorio, pues de una estructura centralista heredada del siglo XVIII se pasó con la Constitución de 1978 a la España de las Autonomías. En una de las principales obras dedicadas a analizar este proceso se afirmaba que la organización y el modelo territorial «que surge a partir del consenso constitucional es un sistema de organización que, pese a reconocer la variedad regional y la existencia de nacionalidades en su título preliminar, pretende poner las bases de un sistema uniforme de organización territorial», un sistema con disparidades regionales y desigualdades territoriales (García y Sotelo, 1999: 17). Un sistema que, aun-

10 Las dos Alcarrias la han recorrido A. Villaverde y R. Torres: Viaje a las Alcarrias (2006). 
que no ha marcado diferencias entre regiones y nacionalidades, ha originado un Estado de las Autonomías asimétrico debido, entre otras cosas a la presencia de la foralidad vasca y navarra. En pleno debate sobre la posibilidad de llevar a cabo un Estado Federal (¿simétrico o asimétrico?), parece que sus defensores lo que proponen es la asimetría: naciones y comunidades autónomas.

El primer viaje por la totalidad de la España de las Autonomías lo realizó Manuel de Lope, que tras haber estado ausente de su país durante dos décadas, por razones del exilio familiar, nos ofrece una obra en dos volúmenes: Iberia. La puerta iluminada (2003) e Iberia. La imagen múltiple (2005). Se trata de un recorrido hiperrealista por las 17 Comunidades Autónomas, por un país que está viviendo de forma apasionada su nueva situación en el mundo, distinta a la España que conoció cuando la abandonó en 1969. En sus descripciones se mezclan vivencias, paisajes, consideraciones artísticas, todo ello a través de descripciones llenas de minuciosidad y plasticidad. Nos detendremos únicamente en algunas de las capitales de las Comunidades: La Coruña «las casas de miradores blancos.... ciudad agradable». Santander «La ciudad ha crecido en dos direcciones». Logroño «es una ciudad próspera...sin perder las dimensiones confortables de una capital de provincias tradicional». Zaragoza «La metrópoli aragonesa parece haber crecido a golpes, desbordando los sucesivos cinturones y avenidas que alternativamente rodean y estrangulan las ciudades modernas». Valencia «La ciudad ha crecido y se ha ampliado sobre el terreno de lo que era su Huerta». Sevilla «hubiera podido ser la corte del rey de España». Mérida «conserva algunos de los restos romanos más importantes de España». Y Palma de Mallorca «a pesar del prestigio que recibe el veraneo real, el abuso inmobiliario produce una impresión de hacinamiento». Seleccionaremos un texto sobre Murcia en el que se juega con la conjunción de los distintos leguajes artísticos:

«La ciudad está situada en terreno llano, en la comarca ancha y fértil de la vega inferior del Segura. Murcia no es una ciudad monumental. Sin embargo, tiene un encanto entre italiano y colonial. La primera apreciación viene dada casi exclusivamente por la portada barroca de la catedral, que recuerda las fachadas de las iglesias napolitanas... La portada de la catedral de Murcia y el esquinazo de Moneo son edificios más complementarios que contradictorios, que actúan como antenas parabólicas emitiendo desde sus respectivas antípodas mensajes o lecciones para un curso superior de arquitectura» (Lope, 2003: 335-338).

María Rubio ha hecho hincapié en el boom de los libros de viajes, pues de hecho muchas Comunidades Autónomas han podido publicar antologías con textos de viajeros a lo largo del tiempo. En otro artículo sobre los límites de los libros de viajes afirma que hoy lo que interesa no es el viaje sino lo que queda del viaje «el libro de viajes deja de ser la transcripción de una visita para convertirse en la enumeración del cúmulo de sensaciones» (Rubio, 2004 y 2011: 81), algunos ejemplos de lo dicho, con una cierta carga neo-romántica, lo hemos podido comprobar tras su lectura, en el neerlandés Cees Nooteboom con su obra El desvío a Santiago (1992), donde recorre en automóvil el país sin itinerario, a través de la historia, la literatura, el arte y las costumbres, quedando en un lugar muy secundario los paisajes, que aparecen como meras referencias; y con 
Alfonso Armada en España, de sol a sol (2001), en cuyo recorrido va dando grandes saltos por el país, tomando como punto de partida a Madrid, con escaso interés paisajístico.

El neo-romántico con mayor peso actual en la literatura de viajes es Julio Llamazares, que tras escribir distintas novelas basadas en sus lugares de referencia vital y haber realizado viajes por zonas y comarcas ${ }^{11}$, emprenderá en el mismo año dos proyectos: en primer lugar El viaje de Don Quijote desde La Mancha a Barcelona ${ }^{12}$, y por último su Atlas de la España imaginaria (2015) donde se recogen textos publicados en La Vanguardia con fotos de Navia. Según el prologuista Pedro García, el autor «contrasta la lírica de la fantasía con la realidad prosaica. Desmitifica la toponimia mágica». Aparecen una serie de lugares, sin orden geográfico, que están relacionados con dichos importantes de la lengua castellana o con autores clásicos: La Ínsula Barataria de Cervantes la relaciona con los pueblos aragoneses de Alcalá de Ebro o Pedrola. Babia o «estar en Babia», es una tierra bañada por el río Luna, en el noroeste de León, considerada por el autor como un «paraíso escondido». Las Batuecas se identifica con un pequeño valle perdido al sur de la provincia de Salamanca. En el centro destaca «entre Pinto y Valdemoro» una realidad madrileña que parece fruto de la imaginación, aunque en realidad son dos pueblos que tienen poco que ofrecer, pues «importa poco su realidad». Los cerros de Ubeda presentan cerros cantados por distintos poetas y una ciudad «de las más bellas de toda España». Jauja, entre Córdoba y Sevilla, es una pequeña aldea cordobesa que se asienta en un meandro del río Genil, «la tierra de Jauja» de la que hablaba Lope de Rueda. Y por último, Fuenteovejuna, inmortalizada por Lope de Vega:

«hoy no es ni la sombra de lo que fue. Mermada su población, como las de sus catorce aldeas, por el éxodo emigratorio de la segunda mitad del siglo pasado y trasladadas muchas de sus familias ricas a Córdoba. Fuente Obejuna hoy languidece aferrada a unas estructuras económicas que ya no sirven para mantenerla en pie» (Llamazares, 2015: 75).

Ente los viajeros españoles por el extranjero como fue el caso durante las últimas décadas, entre otros, de Leguineche ${ }^{13}$, queremos destacar para concluir, la reciente aportación del geógrafo Fernando Manero en sus recorridos por la América austral, cuando señala que el viaje consiste en «aproximarse con la mirada atenta a lo que la realidad ofrece... nada de lo que sucede en el territorio, concepto determinante en la formación y transformación de los paisajes, en su dimensión natural y cultural, es indiferente a las apetencias intelectuales del geógrafo cuando decide acometer un viaje, máxime si se tiene en cuenta que el viaje constituye un componente básico de su actividad profesional» (Manero, 2015: 22 y 26).

Para terminar, recordaremos que Rull y Serrallonga (2008) dijeron que viajar = vacaciones ha alcanzado hoy su máxima expresión con la industria del turismo, desapareciendo la figura del viajero que ha quedado reservada para las grandes aventuras. Creemos haber demostrado que los viajeros han seguido su evolución, con independencia del turismo.

11 Julio Llamazares: El río del olvido (1990), Tras-os-montes (1998) y Cuaderno del Duero (1999).

12 Julio Llamazares: El Viaje de Don Quijote. El País: 31 de julio a 30 de agosto de 2015.

13 Manuel Leguineche: La vuelta al mundo en 81 días (1988) 


\section{CONSIDERACIONES FINALES}

En el largo proceso de viajes por España, tanto de extranjeros como de españoles, nos aparecen claramente dos etapas: la primera, que va desde mediados del siglo XVIII hasta los años cincuenta del siglo XX, y la segunda, desde ese momento hasta la actualidad.

Durante la primera y larga etapa, fue fundamental la aportación que ofrecieron sobre nuestros territorios y paisajes los extranjeros que nos visitaron. Cuando llegaron los primeros viajeros, las mulas y los carros de bueyes con grandes discos macizos en lugar de ruedas, dieron paso a nuevas formas de realizar los recorridos: carros de caballos, diligencia y luego el ferrocarril. Lo primero que destacaron los viajeros que nos conocieron bien fue la corrupción existente, así como las grandes diferencias, tanto paisajísticas como sociales. Confrontaron tres tipos de paisajes muy distintos: las montañas de Gredos y del Cantábrico; Castilla, tanto la Vieja como la Nueva, les pareció decepcionante, sin árboles, monótona y desértica; y por último, el levante mediterráneo y en menor medida Andalucía donde aparecen tierras bien regadas, fértiles llanuras, zonas feraces y terrenos magníficamente cultivados. Respecto a las ciudades, no cabe duda que la que ocupaba el primer lugar por su modernidad, belleza de conjunto, sentido de capitalidad y buen puerto era Barcelona; por el contrario Madrid representaba el atraso, tan sólo el Museo del Prado la salvaba. Las restantes ciudades, unas destacaban por su catedral, otras por su antigüedad, o por su arquitectura monumental aunque en abandono. Andalucía representaba el exotismo pero también la desigualdad social y la necesaria transformación de su riqueza agraria. Los viajeros españoles, por el conjunto del país, supieron descubrir pequeños territorios, comarcas olvidadas como fue el caso de Las Hurdes, La Vera y La Alpujarra.

La segunda etapa, que llega hasta la actualidad, ha venido acompañada con la mejora de las carreteras y los ferrocarriles, y también, por el acceso a nuestro país mediante vuelos que han permitido hacerse una idea de lo que se iba a visitar en automóvil. Un fenómeno que está presente desde el principio hasta el día de hoy es nuevamente la corrupción, algo que viene a señalar de forma negativa a nuestro país. Los contrastes paisajísticos siguen marcando las diferencias, ahora con más motivo con el paso de la España centralista a la autonómica: el verdor de la cortina cantábrica, las fértiles tierras valencianas, los campos andaluces cuidadosamente cultivados y el llano y seco interior castellano. Respecto a las grandes ciudades, mientras Madrid ha dado un paso importante, pues de ser una capital anodina hoy es una ciudad moderna; por otro lado, Barcelona se consolida como gran ciudad industrial y metropolitana, con el puerto más transitado; Sevilla es la más bella; Toledo, la vieja ciudad imperial ha pasado de sombría y extraña a recuperar su grandeza; y por último, la singularidad de un buen número de núcleos urbanos. Nuevamente, una serie de viajeros españoles por el conjunto del país han venido a destacar algunas comarcas, este es el caso de La Alcarria y La Mancha.

Si el objetivo fundamental de la literatura de viajes ha sido analizar la descripción de paisajes, comprobamos como éstos han ido evolucionando desde el interés por lo natural, lo rural, para finalmente centrarse en lo urbano. Este mismo proceso se ha observado en la literatura en general, especialmente la novela, pues la imagen literaria del paisaje observó los naturales, rurales y con el tiempo, los paisajes urbanos, sin olvidar las comarcas literarias (Pillet, 2015 b y c). Estos aspectos vienen a coincidir con la evolución que se 
está siguiendo en el estudio del paisaje o de los paisajes culturales donde en la actualidad interesa su valor como legado, su patrimonialización, pues el paisaje «deberemos vincularlo al del propio patrimonio en sus múltiples tipologías, pero sobre todo con el que las engloba todas, el patrimonio territorial», tal y como ha afirmado Cañizares (2014: 174).

\section{BIBLIOGRAFÍA}

ALARCÓN, P. A. (2001): La Alpujarra. Madrid. Miraguano-Polifemo

ALARCON, P. A. de (1883): Viajes por España. Madrid, Imprenta Subrull.

ALARCÓN, P. A. de (1926): De Madrid a Nápoles. Madrid, Sucesores de Rivadeneyra. ANES ÁLVAREZ, G. (1969): Economía e Ilustración. Barcelona, Ariel.

ARMADA, A. (2001): España, de sol a sol. Barcelona, Península.

ARTOLA, M. (1977): La burguesía revolucionaria (1808-1874). Madrid, Alianza.

BIBLIOTECA NACIONAL DE ESPAÑA (2013): Libros de viaje y viajeros de los siglosXVI-XIX. Madrid. Disponible http://www.bne.es/es/Micrositios/Guias/Viajes/resources/docs/Guia_Libros_de_de_viaje_y_viajeros_Siglos_XVI-XIX.pdf $(25 / 06 / 2013)$

BORROW, G. H. (1921): La Biblia en España. Madrid, Jiménez Fraud

BOURGOING, J-F. (2012): Imagen de la moderna España. Alicante, Universidad de Alicante.

BRENAN, G. (1964): La faz actual de España, Buenos Aires, Losada.

CAMBA, J. (2014): Crónicas de viaje. Impresiones de un corresponsal español. Madrid, Fórcola.

CAMPOY, A. M. (1963): Viaje por España. Cómo nos ven los extranjeros. Madrid, Biblioteca Nueva.

CAÑIZARES RUIZ, M. C. (2014): «Paisajes culturales, ordenación del territorio y reflexiones desde la geografía en España». Polígonos. Revista de Geografía, $\mathrm{n}^{\circ} 26$, pp. 147-180.

CAPEL, H. (1975): Capitalismo y morfología urbana en España. Barcelona, Los Libros de la Frontera.

CAPEL, H. (2014): El patrimonio: la construcción del pasado y del futuro. Barcelona, Ediciones del Serbal.

CARRIÓN, J. (2011): «El viajero franquista». Revista de Literatura, n 145, pp. 269-282.

CELA, C. J. (1965): Obra Completa. Viajes por España, Barcelona, Destino, tomos IV a VI.

CELA, C. J. (1978): Obra Completa. Páginas de geografía errabunda, Barcelona, Destino, tomo X.

CERROLAZA, J. (1993): «El eje Norte-Sur en los libros alemanes de viaje por España». Revista de Filología Alemana, $\mathrm{n}^{\circ}$ 1, pp. 25-35.

CHUECA GOITIA, F. (1968): «La época de los Borbones», en García y Bellido, A. et al. Resumen histórico del urbanismo en España, Madrid, Instituto de Estudios de Administración Local, pp. 211-248.

DAUZAT, A. (1911): L'Espagne telle qu'elle est. Paris, F. Juven.

DAVILLIER, CH. y DORÉ, G. (1998): Viaje por España. Madrid, Miraguano, 2 vol. 
DOS PASSOS, J. (1943): Rocinante vuelve al camino. Buenos Aires, Santiago Rueda,

FARINELLI, A. (1920): Viajes por España y Portugal desde la edad media hasta el siglo $X X$. Madrid, Centro de Estudios Históricos.

FERNÁNDEZ DE MORATÍN, L. (1991): Viage a Italia. Madrid. Espasa Calpe.

FERRES, A. y LÓPEZ SALINAS, A. (1960): Caminando por las Hurdes. Barcelona, Seix Barral.

FLORES ARROYUELO, F. (1972): La España del siglo XX vista por extranjeros. Madrid, Cuadernos para el Dialogo.

FORD, R. (2008): Manual para viajeros por España y lectores en casa. Madrid, Turner, VII volúmenes.

GARCÍA ALVARADO, J. Ma y SOTELO NAVALPOTRO, J. A. (1999): La España de las Autonomías. Madrid, Síntesis.

GARCÍA ÁLVAREZ, J. y MARÍAS, D. (2011): «Geografía, viajes y periodismo en la España del franquismo: Valeriano Salas y la Revista Geográfica Española», Scripta Nova, vol. XV, no 378, disponible en http://www.ub.edu/geocrit/sn/sn-378.htm.

GARCÍA MERCADAL, J. (1917-1920): España vista por los extranjeros. Madrid, Biblioteca Nueva, 3 vol.

GARCÍA MERCADAL, J. (1999): Viajes de extranjeros por España y Portugal. Desde los tiempos más remotos hasta comienzos del siglo XX. Salamanca, Junta de Castilla y León, 6 vol.

GAUTIER, TH. (1920): Viaje por España. Madrid, Calpe.

GÓMEZ DE LA SERNA, G. (1974): Los viajeros de la Ilustración, Madrid, Alianza.

GOYTISOLO, J. (2010): Campos de Nijar. Barcelona. Vocas Críticas.

GUTIÉRREZ-SOLANA, J. (1998): La España Negra. Granada, La Veleta.

GUTIÉRREZ-SOLANA, J. (2007): La España Negra (II). Viajes por España y otros escritos. Granada, La Veleta.

HUMBOLDT, W. von (1998): Diario de viaje a España 1799-1800. Madrid, Cátedra.

LEGUINECHE, M. (1988): La vuelta al mundo en 81 días. Barcelona, Ediciones B.

LLAMAZARES, J. (1990): El río del olvido. Barcelona, Seix Barral.

LLAMAZARES, J. (1998): Tras-os-montes. Un viaje portugués. Madrid, Alfaguara.

LLAMAZARES, J. (1999): Cuaderno del Duero. León, Edilesa.

LLAMAZARES, J. (2015): Atlas de la España imaginaria. Madrid, Nórdica.

LOPE, M. de (2003): Iberia. La puerta iluminada, Barcelona, Debate.

LOPE, M. de (2005): Iberia. La imagen múltiple, Barcelona, Debate.

LÓPEZ ONTIVEROS, A. (2001): «Caracterización geográfica de Andalucía según la literatura viajera de los siglos XVIII y XIX». Ería, no 54-55, pp. 7-51.

LÓPEZ ONTIVEROS, A. (2006): «Literatura, Geografía y representación del paisaje», en López Ontiveros, A. y Ortega Cantero, N. (Coords.) Representaciones culturales del paisaje y una excursión por Doñana, Madrid, Universidad Autónoma de Madrid, pp. 13-40.

MANERO, F. (2015): Donde los vientos nunca se detienen. Andanzas y enseñanzas viajeras de un geógrafo en América austral. Valladolid. Universidad de Valladolid.

MARAÑON, G. (1994): Viaje a las Hurdes: el manuscrito inédito de Gregorio Marañon. Madrid, El País-Aguilar. 
MARTÍNEZ ALONSO, P. J. (2003): Libros de viajes alemanes e ingleses a España en el siglo XX. Tesis Doctoral, Madrid, Universidad Complutense, Facultad de Filología.

MARTÍNEZ CUADRADO, M. (1976): La burguesía conservadora (1874-1931). Madrid, Alianza.

MESONERO ROMANOS, R. de (1881): Recuerdos de viaje por Francia y Bélgica en 1840 a 1841 Madrid, Oficinas de la Ilustración Española y Americana.

NEVILLE, E. (2011): Mi España particular. Guía arbitraria de los caminos turísticos y gastronómicos de España. Madrid, Reino de Cordelia.

NOOTEBOM, C. (2010): El desvío a Santiago. Madrid, Siruela.

ORTÁS DURAND, E. (2005): «La España de los viajeros (1755-1846): imágenes reales, literaturizadas, soñadas...», en ROMERO, L. y ALMARCEGUI, P (Coords) Los libros de viaje: realidad vivida y género literario. Madrid, Universidad Internacional de Andalucía y Akal, pp. 48-91.

ORTEGA CANTERO, N. (1990): «El paisaje de España en los viajeros románticos». Ería, $\mathrm{n}^{\circ} 12$, pp. 121-137.

ORTEGA CANTERO, N. (2002): «Paisaje e identidad nacional en Azorín». Boletín de la Asociación de Geógrafos Españoles, $\mathrm{n}^{\circ}$ 34, pp. 119-131.

ORTEGA CANTERO, N. (2003): «La imagen literaria del paisaje de España». En MATA, R. y SANZ, C. Atlas de los paisajes de España. Madrid, Ministerio de Medio Ambiente, pp. 30-52.

PARDO BAZÁN, E. (1889): Al pie de la torre Eiffel: (crónicas de la exposición). Madrid, La España Editorial.

PILLET CAPDEPÓN, F. (2012): Planificación Territorial. Propiedad y Valoración Catastral (España 1750-2010). Madrid, Biblioteca Nueva.

PILLET CAPDEPÓN, F. (2015a): «Del espacio geográfico al turismo como uso y disfrute del territorio comarcal: una reflexión teórica desde España». Revista de Geografía Norte Grande, $\mathrm{n}^{\circ}$ 62, pp. 185-201.

PILLET CAPDEPÓN, F. (2015b): «La evolución de la imagen literaria del paisaje urbano: de la ciudad moderna a la ciudad actual». Estudios Geográficos, nº 278, pp. 285-307.

PILLET CAPDEPÓN, F. (2015c): «El Quijote y La Mancha: la evolución de la imagen literaria del paisaje rural». Biblio 3W. Revista Bibliográfica de Geografía y Ciencias Sociales, $\mathrm{n}^{\circ}$ 1112. Disponible en http://www.ub.edu/geocrit/b3w-1112.htm.

PONZ, A. (1988): Viaje de España. Madrid, Aguilar, 4 vol.

PONZ, A. (2007): Viaje fuera de España. Alicante, Publicaciones de la Universidad.

PRITCHETT, V. S. (2015): El temperamento español. Barcelona, Gatopardo ediciones.

ROBERTSON, I. (1988): Los curiosos impertinentes: viajeros ingleses por España desde la accesión de Carlos III hasta 1855. Barcelona, Serbal y Madrid, CSIC.

ROMANO, V. y SANZ, F. (1967): Valle de Alcudia. Madrid, Alfaguara.

RUBIO MARTÍN, M. (2004): «Los libros de viajes en la España de las autonomías». Quimera, n $^{\circ}$ 246-247, pp. 82-89.

RUBIO MARTÍN, M. (2011): «En los límites del libro de viajes: seducción, canonicidad y transgresión de un género». Revista de Literatura, $\mathrm{n}^{\circ}$ 145, pp. 65-90.

RULL, D. y SERRALLONGA, J. (2008): Viajes y viajeros. La aventura de viajar. Desde los orígenes hasta nuestros días. Barcelona, Liberta. 
SERNA, V. de la (1955): Nuevo viaje de España. La ruta de los foramontanos. Madrid, Editorial Prensa Española.

SERNA, V. de la (1960): Nuevo viaje de España. La vía del Calatraveño. Madrid, Editorial Prensa Española.

TORBADO, J. (1990): Tierra mal bautizada. Un viaje por Tierra de Campos. Valladolid, Ámbito.

TORRES CAMACHO, J. N. (2015): «El paisaje como recurso turístico durante el franquismo», en De la Rivas, J. et al, (Eds) Análisis espacial y representación geográfica: innovación y aplicación. Zaragoza, Universidad de Zaragoza-AGE, pp. 1.241-1.250.

TOWNSEND, J. (1988): Viaje por España en la época de Carlos III (1786-1787). Madrid, Turner.

TUÑON DE LARA, M. (1974): La España del siglo XX. Barcelona, Laia, Tomo I.

UNAMUNO, M de (2004): Obras Completas: Por tierras de Portugal y España. Andanzas y visiones españolas. Madrid, Biblioteca Castro. Tomo VI.

VERHAEREN, E. y REGOYOS, D de (1963): España Negra. Madrid, Taurus.

VIERA y CLAVIJO, J. de. (1849): Apuntes del diario e itinerario de mi viage a Francia y Flandes... en los años de 1777 y 1778. Santa Cruz de Tenerife, Imprenta Isleña.

VIERA Y CLAVIJO, J. de. (1976): Dos viajes por España (La Mancha, 1774 y La Alcarria, 1781). Tenerife, Aula de Cultura.

VILLAVERDE, A. y TORRES, R. (2006): Viaje a las Alcarrias. Madrid, Llanura. 
